\title{
Identifying Gifted Preschoolers in Turkey: The Reliability and Validity of the Turkish-translated Version of the GRS-preschool/Kindergarten Form
}

\author{
Filiz Karadağ $\breve{g}^{1}$, Steven Pfeiffer ${ }^{2}$ \\ ${ }^{1}$ Buca Faculty of Education, Dokuz Eylul University, İzmir, Turkey \\ ${ }^{2}$ Education Psychology \& Learning Systems College of Education, Florida State University, Tallahassee, Florida, USA \\ Correspondence: Filiz Karadağ, Buca Faculty of Education, Dokuz Eylul University, İzmir, Turkey.
}

Received: June 22, 2016 Accepted: July 1, 2016 Online Published: July 15, 2016

doi:10.11114/jets.v4i10.1686 URL: http://dx.doi.org/10.11114/jets.v4i10.1686

\begin{abstract}
The reliability and validity of the Turkish-translated version of the Gifted Rating Scales (GRS) were tested on 30 preschool teachers who provided ratings for a total of 390 preschoolers aged ranging from 4 years, 0 months to 6 years, 11 months. Results indicated that the reliability and validity of all five of the GRS-P subscales were high. Confirmatory factor analysis provided support for the five-factor model, corroborating other validation studies. Results found a significant difference in gender for artistic talent and motivation, but otherwise no effect for gender. There was no significant difference across age groups. The present study provides preliminary support for a Turkish-translated version of the GRS-P. Implications for the rating scale's use as a viable screening instrument in Turkey to assist in early, pre-school gifted identification were discussed.
\end{abstract}

Keywords: GRS, gifted identification, pre-school gifted, rating scales

\section{Introduction}

Intelligence has historically been defined by scientists in different ways. According to a study by Sternberg and Detterman (1986), psychologists have defined intelligence as a process of learning and adaptability to one's environment by means of experiences and have extended this definition by emphasizing the importance of meta-cognition and the abiliThe DOI number is 10.11114/jets.v6i12.3566ty of humans to understand and control their own thinking process. In addition to this definition, contemporary researchers have emphasized the importance of culture in defining intelligence, and have dwelled upon that a feature, defined as intelligence in a culture, can mean nonsense in another culture (Sternberg, Jarvin \& Grigorenko, 2010).

The changing definitions of intelligence overtime has reflected itself in redefining giftedness, and there is a variance from traditional definitions to contemporary definitions. For example, Giftedness has been defined with conception and tests of intelligence since the late 19th century. Individuals with intelligence quotients 130 and over were defined to be gifted. However, measuring intelligence based only on verbal and mathematical performance showed that these were insufficient in defining giftedness and thus, there appeared a necessity of new definitions. In the beginning of the 20th century, giftedness was almost always used synonymously with the term "genius". Mentioning the high grades to be obtained from the tests including academic matters mainly in this period, the term "giftedness" has broadened its scope to include ability to solve problems, incentive, skill, creativity, leadership, etc. with the turn of this century (Levent, 2013; Pfeiffer, 2008; Sak, 2014; Sternberg, Jarvin \& Grigorenko, 2010) and this trend in defining the term has been supported by many theoreticians in the field including Sternberg \& Zhang (1995), Renzulli (1999), Tannenbaum (1986), Feldhusen (2005), Csikszentmihalyi (1996), Winner (1996), Gruber (1981), Gardner (2000, 2001), and Gagne (2000).

This change in definition of giftedness has caused some amendments on the definition of superior intelligence. Identifying superior-intelligent children includes the process of collecting data on intelligence, creativity and achievement followed by making decisions about the cognitive capacities or potentials of children in line with those data (Sak, 2014). Identification has critical importance in providing educational opportunities for these children (Matthew, Golin, Moore \& Baker, 1992). Early identification is a process which helps the gifted child interiorize a 
regular studying system by promoting to use the potential and conduces to enable the family and teachers to make arrangements to support the students to utilize their interests and abilities to a high level (Cutts \& Moseley, 2004).

Identifying gifted individuals is highly supported in the field of education; it is, however causing certain debates (Heller \& Schofield, 2008). These debates crawl around the true indicators (features or skills) of superior intelligence, the potential reasons for identifying gifted students, the scales, tools and methods used in measuring intelligence and the timing for identification, i.e. at which stage of development should the children be identified. In short, the questions of what, why, how and when have begun to come to the fore with an increased interest in identifying the gifted (Pfeiffer, 2008).

The rapid growth and development of children in the first six years of life is considered to be a basic obstructing factor in the identification process in this period of the human life span. Related discussions include of the types of scales that may be used for this age range as well as the person(s) who may be authorized to decide on children's giftedness (Sutherland, 2008).

Two points should be tackled regarding the question "When can a gifted child be identified?" The first one is "Is it possible to identify these children in the earliest period of development or, in other words, during preschool or the beginning of primary school period?", and the second one is "Must the identification process be carried out intermittently or constantly?" As explaining in detail, "Must the process be repeated throughout the life span in order to revise the educational program or is only one time identification enough?" Correspondingly, as mentioned before, the other problem is that the identification is realized compulsorily or voluntarily by means of the school system (Heller \& Schofield, 2008). According to the literature, considering the importance of early social-emotional and the academic support, children should be identified as early as possible (Schofield \& Hotulainen, 2004; Stapf, 2003). Based on studies on the development of superior-intelligent children, Lehwald (1986) mentions that the critical point in early identification is to determine the most appropriate thing for the development of the child. In addition, he points out that it is nearly impossible to support the development of the child without adequate knowledge of the identification criteria for superior intelligence and that the contribution of the pre-school teacher as well as the child psychologist is significant in the early identification process (Lehwald 1986; cited by Heller \& Schofield, 2008).

Today, two different scaling types, namely psychometric scales and ability-based assessment scales are commonly utilized to identify gifted individuals (Heller, 2001; Pfeiffer, 2008; Heller, Perleth \& Lim, 2005). Psychometric scales focus generally on the potential features of the children suitable for the identification criteria while the ability-based assessment scales, used by experts, mostly on the personal learning and motivation features and partly on socio-cultural structure. Together with these assessment tools, it is considered necessary to use more than one measure In addition, more than one tool is used and the opinions of various individuals are obtained in order to identify the superior intelligence potential of children due to their general features in the preschool period. Among them are peer assessment, observation forms, anecdotal records, developmental scales and teacher assessment scales (Sutherland, 2008).

Obtaining teacher opinions as a way of identifying gifted students has become a widely used method in recent years. Past researches have shown that teacher prejudice against cultural differences resulted with misidentification of potentially gifted children (Davis \& Rimm, 2003; Kaufman \& Harrison, 1986). However, the benefits of teacher observations over parents in identifying gifted children have been well documented, and have been found to show that teachers that have more right in determination than the families in a study making benefit of observations of teachers and families to determine the gifted children. This is especially in recent years where it has been emphasized as significant in order to determine the gifted children due to the fact that the teacher assessment scales are being developed and that the observations of teachers are the most detailed ones carried out in the long-term (Jarosewich, Pfeiffer \& Morris, 2002; Pfeiffer, 2015). As related assessment scales and checklists are becoming more and more objective, the teachers can obtain information related to the assessment of the behaviors indicating the giftedness among their students through the better standardized tests (Chan, 2000; Hodge \& Cudmore, 1986). Accordingly, studies emphasize a preference for using teacher scales in identifying potentially gifted children. Currently, studies on three commonly used scales have put forth several concerns regarding psychometric and clinical issues (Jarosewich, Pfeiffer \& Morris, 2002), claiming the need to develop a practical, reliable and valid assessment scale for teachers in order to assess student behaviors indicating superior intelligence. The Gifted Rating Scale (GRS) is one such assessment tool (Pfeiffer \& Jarosewich, 2003), followed recently by the Teacher Rating Scales: the Gifted and Talented Evaluation Scale (GATES; Gilliam, Carpenter \& Christensen, 1996), the HOPE Scale (Peters \& Gentry, 2009), and the Scales for Identifying Gifted Students (SIGS) (Ryser \& McConnell, 2004) (Yang, 2009). However, no standard test to be used by teachers is currently available for the Turkish population.

The GRS includes a Preschool/ Kindergarten Form (GRS-P) for ages 4:0 to 6:11 and a School Form (GRS-S) for ages 6:0 to 13:11. Gifted Rating Scales- Preschool/Kindergarten Form (GRS-P), developed by Pfeiffer and Jarosewich (2003) 
is based on a multiple assessment model (Munich Model of Giftedness) (Zigler \& Heller, 2000) in order to determine gifted preschoolers. The Alpha reliability coefficient of the original scale is between .97 and .99 , for 5 different age ranges and includes 6 sub-scales. The criterion related validity of the scale was tested using the Wechsler Preschool and Primary Scale of Intelligence-Third Edition (WPPSI-III) and revealed good estimates. For the purpose of identification validity of the scale, Wechsler Preschool and Primary Scale of Intelligence-Third Edition (WPPSI-III) was applied to 124 children - 68 males and 59 females - as well as GRS-P scale. Moreover, the construct, concurrent, and predictive validity has been realized. The correlations among the GRS subscales showed the highest relation to be between the intellectual ability subscale and the academic competence subscale with a correlation coefficient of .93. The correlation coefficients between academic competence/creativity and intellectual ability/creativity subscales were found to be .86 and .85 , respectively. Pfeiffer, Petscher \& Jarosewich (2007) compared the scores obtained by children in all GRS subscales across child age and gender and found no significant differences for age and gender with the exception of gender differences on the artistic ability subscale. ANOVA test was performed in order to determine whether the grades, obtained from sub-scales of GRS-P, vary significantly according to the genders and ages of the children or not. As per this test, it was seen that there was a meaningful difference between male and female students in the artistic ability subscale $\left(F(1,333)=8.23, p<.01, T^{2}=.02\right)$.

However, it was observed that there was no significant difference on the grades obtained from sub-scales of intellectual ability, academic ability, creativity or motivation. It was seen that the points obtained from sub-scales of GRS-P had not significant difference according to the age ranges of the children.

The Chinese version of Gifted Rating Scale-Preschool/Kindergarten Form was adapted by Siu (2010), and compared across age and gender. The sample of the study consisted of 43 teachers and 250 children in 7 different preschool institutions in Hong Kong. The GRS-P and a School Performance Evaluation (SPE) scale developed by the researcher were used to collect data. The split-half reliability coefficients are .98 for the intellectual ability, creativity, and artistic ability subscales and .97 for the motivation subscale. Results involving correlations among the subscales showed that the highest correlation was found between the intellectual ability and the academic ability subscales (.93), while the lowest was between the academic ability and the artistic ability subscales (.85). Results from the confirmatory factor analysis revealed a five-factor model in original form accorded more than the one-factor model. Lastly, positive and high correlations between GRS-P and SPE yielded satisfactory criterion related validity.

The above findings point to the fact that GRS preschool and elementary versions are successful measurement tools across different cultures. The lack of such a tool for the Turkish population of potentially gifted preschoolers and the strength of GRS-P in other cultures calls for an adaptation of this scale to the Turkish population. Therefore the main purpose of this study was to test the psychometric properties of the Gifted Rating Scale-Preschool/Kindergarten Scale (GRS-P) on a Turkish sample. The authors also aimed to compare the data obtained from the sample across child age and gender.

\section{Method}

\subsection{Population}

The sample consisted of 30 preschool teachers (of a total of 390 preschoolers) working in one of the 15 preschools across Izmir during the 2014-2015 school year. All participants had a bachelor's degree in preschool education. The students consisted of 189 girls (48.5\%) and 201 boys (51.5\%) are aged between 4-6 years. $11(2.8 \%)$ students were in 4:0- 4:5 age group, $52(13.3 \%)$ in 4:6-4:11 age group, $99(\% 25,4)$ in 5:0-5:5 age group, $144(\% 36,9)$ in 5:6-5:11 age group and, $84(\% 16,9)$ in 6:0-6:11 age group.

A pilot study was conducted with 3 preschool teachers of a total of 59 preschoolers (33 girls [55.9\%], 26 boys [44.1\%] aged between 4-6) attending two different preschools in Izmir. 2 of the students $(3,4 \%)$ participating in the study are 4:6- 4:11 age group, 19 of them $(32,2 \%)$ are 55:6-5:11 age group, and 10 of them (16,9\%) are 6:0-6:11 age group.

\subsection{Instrumentation}

The Gifted Rating Scale Preschool/Kindergarten Form, developed by Pfeiffer \& Jarosewich (2003), aims to determine potentially gifted children during their preschool years in order to support the already existing identification system. The scale is filled out by teachers and is one that is applicable to a wide range of ages. GRS-P is based on the versatile evaluation model for gifted children. Enabling the superior intelligence to be examined in a versatile manner, graded by teachers, and consisting of 60 items, it was developed with the aim of determining gifted children during the preschool period or to provide a comprehensive evaluation tool. This scale is a highly effective tool to help in determining individuals with intellectual superiorities regardless of the cut off scores set as 115, 120,125 or 130. The GRS-P scale can be used to evaluate early reading, early language development, complex games and other characteristics of the children by teachers of early childhood, preschool or kindergarten. GRS-P, consisting of 60 articles, divided in groups of 12 for every 
sub-test, is prepared in order to evaluate 4 to 6 year olds' skills in 5 different fields: intellectual skills, academic skills, creativity, artistic skills and motivation. The intellectual ability test measures the ability to think in abstract terms, including calculation speed, calculation accuracy and memory. The academic ability test measures age-appropriate academic skills of the preschooler. The creativity scale measures the originality in thoughts and actions, the ability to create new ideas, and participation in imaginary games. The artistic abilities scale measures the child's abilities to express oneself through drama, pictures and music. Finally, the motivation scale aims to determine the child's enjoyment and intrinsic motivation during a difficult task. The main goal of the Motivation scale is to determine the level of patience, consistency and desire for achievement while performing a task and is not used as an indicator of giftedness. Each item in the scale is graded with a 9 point grading system which is also divided into 3 groups (1-3 below average, 4-6 average, 7-9 above average). The scores are then scored using the T score table found in the GRS-P manual. The child who gets the highest $\mathrm{T}$ grade in one or more sub tests is further compared with the scores of other children. $\mathrm{T}$ scores below 55 (below $69 \%$ ) indicate a low probability, scores between 55-59 (69-83\%) an intermediate level of probability, scores between 60-69 (84-97\%) a high probability and scores above $70(98 \%+)$ indicate a very high probability of superior abilities (Pfeiffer \& Jarosewich,2003).

\subsection{Procedures}

The first step of the study included the language adaptation of GRS-P. Literature on scale adaptation emphasizes that a scale to be adapted to another culture and language firstly be analyzed in its original form in order to avoid any misunderstandings by the potential participants in terms of language-specific vocabulary and phrase structure (Hambleton, 2005). Therefore the authors sent the original English form of GRS-P to two academics working in the field of gifted education. The academics' consent on the appropriateness of the scale for the Turkish population was followed by the translation of the scale by two language experts with a mother tongue in American English and advanced Turkish skills. These two experts were also assisted by two experts in gifted education with English language proficiency during the translation phase. The translated forms were then merged into a single form by the former author and this single form was further analyzed once again by the two academics and a third researcher in gifted education. The form was later checked for language and cohesion by two different Turkish language experts Following the necessary revisions, reverse translations were conducted by two different language experts proficient in both languages and who were blind to the former language procedures. The backward translations were analyzed and revised in accordance with the suggestions of two gifted education experts and a researcher working in the field. The final reverse translation and the Turkish form were further compared by two academics specialized in gifted education, one in special education, and one in English language teaching and all agreed on the high conformability level between the two forms. In addition, the reverse translation and the Turkish forms of GRS-P were sent to the Pearson Publication where the translation rights were purchased by the authors. The language adaptation procedures were completed with the confirmation letter of the company.

During the second phase of the study, a pilot study was carried out to determine item correlations and language appropriateness. After the official permission was obtained from the Provincial Directorate for National Education of İzmir, three schools across Izmir were chosen and the former author gave seminars to the teachers working in those schools on giftedness, general characteristics of gifted children in the preschool period and the use of the GRS-P scale. Three preschool teachers joined the pilot study and filled out GRS-P for their students. The Cronbach Alpha calculated for item analysis and reliability was found to be .98 , a finding confirming the applicability of the scale on another sample.

Based on the above findings, the main study began with the same stages performed in the pilot study, this time for a bigger sample including 30 preschooler teachers of a total of 390 students. The data obtained was analyzed via SPSS 22.0 and AMOS 22.0 software.

\section{Results}

In compliance with the results of the pilot study of the GRS-P scale, a main sampling application was carried out and analyzed. Different thoughts exist regarding the sample size in scale adaptation studies. Bryaman \& Cramer (2001) factor analysis indicates that when determining the sample number, a sample of the number obtained from multiplying the number of articles of the scale with five or ten will be enough. On the other hand, Kline (2014) states that the number of sample may vary according to the factor structure, and a 200 person sample will be enough, in fact, it will be appropriate to create a 100 person sample when the factor structure is sufficient. In this context, the number of data obtained was found to be adequate.

The normal distribution curve diagrams and the skewness and flatness values of the sub tests of the GRS-P that the data fulfilled the assumptions of normality. Below are the results pertaining to the validity and reliability of the Turkish Version of GRS-P followed by group comparisons across child age and gender. The following analysis was conducted according to the types of validity evidence as described in the Standards for Educational and Psychological Testing 
(American Educational Research Association, American Psychological Association, \& National Council on Measurement in Education, 1999). With this purpose, in order to determine whether the T scores differ in accordance with gender and age variables, One-Way ANOVA carried out the expert opinion analysis and correlation analysis among the sub tests of the scale to determine content validity, a fit factor analysis to determine the scale's construct validity and the Cronbach Alpha reliability analyses to determine the internal consistency reliability. An alpha level of .05 was used for all statistical tests, unless otherwise stated.

\subsection{The Reliability of GRS-P}

The Cronbach Alpha, preferred as a measure of internal consistency in this study, was calculated to gain information on the consistency of scores attained from each item with the overall scale scores (Crocker \& Algina, 1986). The Cronbach Alphas computed for each of the five subtests were observed to be high (Table 1). In addition the Guttman Split-half reliability coefficient was .96 for Intellectual Ability, .95 for Academic Ability and Creativity and .97 for Artistic Talent and Motivation subtests, which are similar to those reported in the GRS manual (Pfeiffer \& Jarosewich, 2003) as well as a study by Siu (2010) study using a Chinese sample in China.

\subsection{The Validity of GRS-P}

\subsubsection{Content validity}

Content validity is the extent to each item on a scale as well as the whole scale serves the intended purpose of the scale (Creswell, 2013) and is usually determined on the basis of expert opinions (Tekin, 1977). The content validity of the Turkish version of GRS-P in this study was achieved through consulting the opinions of four experts of whom two were from the field of gifted education, one from special education and one from psychological counseling and guidance, with all experts stating that the items on the scale measured the construct adequately. An examination of correlations among the subscales (see Table 1) also supported these expert opinions.

\subsubsection{Scale Correlation Analysis and Factor Analysis}

Pearson product-moment correlations were computed for the five subscale scores of the Turkish-translated GRS-P (see Table 1). These coefficients were observed range between .57 (Intellectual Ability and Artistic Talent subscales) and .90 (Intellectual Ability and Academic Ability subscales) and all were significant at the $p<.01$ level.

Table 1. Internal Consistency Reliability and Bivariate Correlation Coefficients of the Scores of the Turkish Version of the Gifted Rating Scales-Preschool / Kindergarten Form

\begin{tabular}{|c|c|c|c|c|c|c|}
\hline Internal Consistency Subscale & Reliability & 1 & 2 & 3 & 4 & 5 \\
\hline 1 & .98 & 1 & & & & \\
\hline 2 & .96 &, $90^{* *}$ & 1 & & & \\
\hline 3 & .97 & $80^{* *}$ &, $80^{* *}$ & 1 & & \\
\hline 4 & .98 &, $57^{* *}$ &, $58^{* *}$ & $65^{* *}$ & 1 & \\
\hline 5 & .98 &, $82^{* *}$ &, $81^{* *}$ &, $72^{* *}$ &, $64^{* *}$ & 1 \\
\hline
\end{tabular}

Note: 1= Intellectual Ability, 2=Academic Ability, 3=Creativity, 4= Artistic Talent, 5=Motivation.

$* * \mathrm{p}<.01$

The factor structure of the scale was tested via first level Confirmatory factor analysis, using the AMOS program. Multiple fit indexes were used to assess model fit, including $\chi 2 / \mathrm{df}$ ratio, comparative fit index (CFI), normed fit index (NFI), relative fit index (RFI), root mean square residual (RMR), and root mean square error of approximation (RMSEA). The evaluation of the CFA was made with the model conformity index and by a hierarchical measurment model. The chi-square conformity value $(\chi 2=4855.448 ; \mathrm{Sd}=1656 ; \mathrm{p}=.00)$ of the factor construct consisting of 60 items and five sub factors were found to be meaningful and the $\chi 2 / \mathrm{df}$ value regarding the model conformity was computed as 2.932. Other conformity index values were computed as follows: RMSEA: .070, RMR: .099, NFI: .882, CFI: .919, RFI: .874. The $\mathrm{X}^{2} / d f$ value being below 3.0 indicates a decent model conformity level. According to Hu and Bentler (1998), The CFI, NFI and RFI values being close, equal or above .90 are acceptable values, the RMR value being close to 0 means there is a better model conformity and a RMSEA value between .60 and 1 shows that the model conformity is decent and acceptable (Hu \& Bentler, 1998). In light of these values reported by Hu and Bentler, the GRS-P Turkish Version can be considered as a valid measure of preschool giftedness for a Turkish population.

\subsection{Analysis by Gender and Age}

In order to determine whether the T scores obtained from the GRS-P subscales differ for child age and gender, a t-test for gender and a one-way ANOVA for age were performed. According to the results, significant differences were observed for age only on the Artistic ability and Motivation subscales, with girls obtaining significantly higher scores compared to boys (see Table 2). Results of group comparisons for age revealed no significant differences for any subscale. 
Table 2. Means, Standard Deviations, and t-Test by Gender

\begin{tabular}{lcccccc}
\hline & \multicolumn{7}{c}{ Female $(\mathrm{n}=189)$} & & \\
\hline & $\mathrm{M}$ & $\mathrm{SD}$ & $\mathrm{M}$ & $\mathrm{SD}$ & $\mathrm{t}$ & $\mathrm{p}$ \\
\hline Intellectual Ability & 51.96 & 10.12 & 52.19 & 8.81 &,- 23 & .81 \\
Academic Ability & 50.82 & 10.10 & 51.57 & 8.28 &,- 79 & .42 \\
Creativity & 50.43 & 10.98 & 50.08 & 9.42 &, 33 & .74 \\
Artistic Talent & 49.69 & 10.73 & 54.64 & 10.16 & $-4,66$ & .00 \\
Motivation & 49.54 & 10.30 & 51.73 & 9.85 & $-2,14$ & .03 \\
\hline
\end{tabular}

Table 3. Means, Standard Deviations, and Analysis of Variances (ANOVA) by Age

\begin{tabular}{|c|c|c|c|c|c|c|c|}
\hline Age & & & & & & & \\
\hline & $\begin{array}{l}4: 0-4: 5 \\
(n=11)\end{array}$ & $\begin{array}{l}4: 6-4: 11 \\
(n=52)\end{array}$ & $\begin{array}{l}5: 0-5: 5 \\
(\mathrm{n}=99)\end{array}$ & $\begin{array}{l}5: 6-5: 11 \\
(n=144)\end{array}$ & $\begin{array}{l}6: 0-6: 11 \\
(n=84)\end{array}$ & $\mathrm{F}$ & $\mathrm{p}$ \\
\hline Intellectual Ability & & & & & &, 85 & ,49 \\
\hline M & 55,72 & 52,73 & 52,36 & 52,09 & 50,82 & & \\
\hline SD & 13,35 & 12,92 & 9,88 & 8,30 & 7,81 & & \\
\hline Academic Ability & & & & & & 1,52 &, 19 \\
\hline M & 53,18 & 53,15 & 51,81 & 50,81 & 49,58 & & \\
\hline $\mathrm{SD}$ & 13,42 & 12,43 & 10,33 & 7,80 & 6,91 & & \\
\hline Creativity & & & & & & 2,32 & 05 \\
\hline M & 55,18 & 52,30 & 51,40 & 49,32 & 48,63 & & \\
\hline SD & 11,92 & 12,45 & 10,84 & 9,52 & 8,55 & & \\
\hline Artistic Talent & & & & & & 1,28 &, 27 \\
\hline $\mathrm{M}$ & 57,72 & 52,90 & 52,86 & 51,41 & 51,09 & & \\
\hline SD & 13,28 & 13,31 & 11,85 & 9,25 & 9,46 & & \\
\hline Motivation & & & & & & 1,914 & , 107 \\
\hline M & 54,90 & 51,51 & 51,05 & 51,04 & 48,20 & & \\
\hline SD & 51,51 & 12,49 & 11,05 & 9,09 & 8,41 & & \\
\hline
\end{tabular}

4. Discussion

This study investigated the reliability and validity of the Turkish-translated version of GRS-P and explored the possible effects of gender and age on each of the subscales. The Cronbach Alpha values for the adapted GRS-P sub scales were found between .96 and .98, and all Guttman Split-Half internal consistency parameters varied between .95 and .97 . When these findings were examined, it was concluded that all subtests of the scale held high levels of internal consistency reliability. The study carried out by Pfeiffer, Petscher \& Jarosewich indicated that the Cronbach Alpha values of all subtests of the scale varied between .97 and .99 .

This result has shown that the GRS-P original form has given reliable results in the United States as well. The study performed by Sui (2010) has shown that the GRS-P scale's Chinese adaptation had an internal consistency value between .98 and .99 . According to these results, the sub scales have shown high internal consistency reliability similar to that of United States and China studies.

The opinions of two gifted education experts, a special education expert and an academic in psychological counseling and guidance were obtained for the GRS-P's content validity. According to the opinions of the experts, it was concluded that the on the scale measured the target construct. Also, comparing the measured subject and behavior to the test content for content validity, is related to the level of representation the articles provide for the evaluated fields (Naglieri \& Das, 1997). With this purpose, the content validity in our study revealed the relation of the sub scale to the GRS-P scale it belongs to and the relations corrected based on the sub scale's total score. The Pearson product moment correlation factor was used for these calculations. Results showed that the strongest relationship was between the intellectual ability and the academic ability subscales. This strong relationship was observed in the Chinese ( $\mathrm{r}=93$ ) and the American ( $r=93$ ) cultures as well (Pfeiffer et. al., 2007; Siu, 2009). As is stated in the GRS-P manual, the skills and behaviors expected from the intellectual ability and academic ability fields are quite close in nature (Pfeiffer \& Jarosewich, 2003). Thus it is no surprise to observe this high correlation between these two subscales. The lowest correlation among the GRS-P subscales were found between the intellectual ability and the artistic ability subscales $(\mathrm{r}=.570 ; \mathrm{p}<.01)$ and the academic ability and the artistic ability subscales $(\mathrm{r}=.584 ; \mathrm{p}<.01)$. These results also showed correspondence with the American and the Chinese population (Pfeiffer et. al., 2007; Siu, 2010).

As indicated in the GRS- user manual, the expected skills and behaviors on different ability domains such as intellectual, academic and artistic differ from each other (Pfeiffer \& Jarosewich, 2003). Therefore, our results were of no surprise.

Parallel with the original form as well as the Chinese version of the scale, the Turkish version of the GRS-P supported the 5 factor model (Pfeiffer \& Jarosewich, 2003; Siu, 2010) as was observed with the CFA. Findings of our study showed that the Turkish version of GRS-P had a five factor structure, a similar finding with the Chinese and the original GRS-P versions. For the Chinese version, Sui (2010) tested both a one factor and a five factor structure for the scale and 
concluded that the five factor structure was supported with Chinese sample. A similar factor structure across three different samples from three different cultures implies that GRS-P displays universal characteristics and this may be considered proof for the validity of the Turkish version of GRS-P.

Results showed that the Turkish version of the GRS-P subscale scores for the intellectual ability, academic ability and creativity subscales did not differ across gender, where significant differences were obtained in the artistic ability and motivation subscales on behalf of girls. The Pfeiffer and colleagues (2007) study however reported gender differences only for the artistic ability subscale, while the Siu (2009) study revealed none for any subscale.

The analyses regarding child age did not reveal any significant differences across the subscales. The GRS-P evaluates children within their own age range. Thus the results showed that teachers rated their students in a developmentally appropriate perspective. The study by Pfeiffer, Petscher and Jarosewich (2007) similarly proved no meaningful difference among scores in terms of age while Sui (2010) found meaningful differences between age groups 4:6 and 4:11, 5:0 and 5:5, and 5:6 and 5:11 in the "intellectual ability" subscale, 4:6 and 4:11, and 5:6 and 5:11 in the "creativity" subscale, 4:6 and 4:11, 5:6 and 5:11 in the "artistic ability" subscale and 4:6 and 4:11, 6:0 and 6:5 in the "motivation" subscale. Based on these findings, Sui (2010) interpreted that the intellectual ability, creativity and motivation subscales were relatively critical subscales in characterizing a child as one with superior abilities/gifted.

When we look into the research results, it can be concluded that there are deficiencies in the determination, characterization and support of the gifted individuals during the preschool period in Turkey. As stated before, there are no instruments for identifying potential gifted preschooler in Turkey, to date. The psychometric properties of the Turkish version of GRS-P found in this study shows that this scale can be used in the identification of potential Turkish gifted preschoolers. There is also an important advantage of GRS-P in that it is filled by an adult whom the child spends most of her day with. Therefore the data resource the scale uses is someone who knows the child well. Taken together, these arguments may be considered as strong indicators that GRS-P is an appropriate instrument for identifying gifted Turkish preschoolers.

Considering the fact that identifying and supporting gifted preschoolers is one area in which Turkey has problems, the Turkish Version of GRS-P adapted in this study may be considered a reliable and valid measure for identifying gifted Turkish preschoolers which may be taken as a sound start. Once gifted preschoolers are identified with valid and reliable measures, educational programming will be triggered and since the Turkish Version of GRS-P fits a five factor model, children's performance across these 5 abilities will be identified and educators will have the opportunity to plan individualized programs for each gifted child.

Turkey's socio-political structure is heterogeneous in nature with various cultures, languages and religious perspectives. Therefore, a major limitation of this study can be said to be concerned with the sampling procedure, where all data were gathered from a single Turkish metropolitan located in the West region of the country. This may inhibit the use the Turkish Version of GRS-P in other cities across the nation. Thus further studies conducted with a wider sample from different cities may be useful in broadening the use of GRP-P across the nation.

Schooling in the preschool period in Turkey is not a common procedure in Turkey. For example, the 2008 statistics show that only $25 \%$ of children in the kindergarten age attended kindergarten in Turkey. Therefore many gifted preschoolers might be facing the risk of not being identified in the preschool period. Taking this risk into account, identification of gifted children in the elementary period becomes critical. GRS also has an elementary form and the authors suggest studies tackling the psychometric properties of GRS elementary form in the near future.

The preschool form of the GRS scale, which is used frequently in the United States, China, Japan, Korea and Spain in particular, has been adapted into three different languages, and valid and reliable results were obtained. The schooling period form of the GRS scale has been adapted, as stated above, to 5 different languages, and is currently being adapted in Czech Republic and Slovenia. The adaptation of this scale in our country is regarded a great deal of contribution to the subject nationally. Also, it is regarded that it will help fill the gap in the field. With more studies such as this one in the field, the identification methods of gifted children will be versatile.

In further studies, it is recommended that studies to provide deeper correlation analysis with other languages to which the GRS-P has been adapted be carried out, the GRS scale form for the schooling period also be adapted to the Turkish language, the GRS-P scale correlation and the acquisition scales in accordance with the academic, intellectual, artistic abilities and creativity and motivation characteristics of kindergarten students be examined, the correlation between the GRS-P done by teachers and GRS-P done by families be examined. Additionally, it will be beneficial if the children whose abilities in different fields have been identified with the GRS scales are given the appropriate education in fields in which they have shown high potential, and work to contribute to their development in these fields is performed. 


\section{Acknowledgements}

This research was based on a masters' thesis conducted by the first author under the supervision of the second author.

This research supported by "A Diagnostics and Awareness Study on Potentially Gifted Children in Preschool and Primary School" scientific research project.

The proof reading of this research has been done by three native speakers.

We especially would like to thank you to Assist. Prof. Ayşe Dolunay SARICA for her kind help.

\section{References}

American Educational Research Association, American Psychological Association, \& National Council on Measurement in Education. (1999). the standards for educational and psychological testing. Washington, DC: American Educational Research Association.

Bryman, A., \& Cramer, D. (2001). Quantitative data analysis with SPSS release 10 for Windows. New York. http://dx.doi.org/10.4324/9780203471548

Chan, D. W. (2000). Exploring identification procedures of gifted students by teacher ratings, parent ratings and student self-reports in Hong Kong. High Ability Studies, 11(1), 69-82. http://dx.doi.org/10.1080/713669176

Creswell, J. W. (2013). Research Design: Qualitative, Quantitative and Mixed Methods Approaches. Sage.

Crocker, L., \& Algina, J. (1986). Introduction to classical and modern test theory. Holt, Rinehart and Winston, 6277 Sea Harbor Drive, Orlando, FL 32887.

Csikszentmihalyi, M., \& Robinson, R. E. (1986). Culture, time, and the development of talent. In R. J. Sternberg \& J. E. Davidson (Ed.), Conceptions of giftedness (pages 264-284). New York: Cambridge University Press.

Cutts, N. E., \& Moseley, N. (2004). Üstün zekâlı ve yetenekli çocukların eğitimi. (Education of Superior-intelligent and gifted children) İsmail Ersevim (Translation). İstanbul: Özgür Publisher.

Davidson (Ed.), Conceptions of giftedness (pages. 247-263). New York: Cambridge University Press.

Davis, G. A., \& Rimm, S. B. (2003). Education of the gifted and talented (5th edition). Boston, MA: Allyn ve Bacon.

Feldhusen, J. F. (1986). Aconception of giftedness. In R. J. Sternberg ve J. E. Davidson (Ed.), Conceptions of giftedness (pages. 112-127). New York: Cambridge University Press. http://dx.doi.org/10.1017/cbo9780511610455.006

Feldhusen, J. F. (2005). Giftedness, talent, expertise, and creative achievement. In R. J. Sternberg \& J. E. Davidson (Eds.), Conceptions of giftedness (2nd edition, pages. 64-79). New York: Cambridge University Press.

Gagne, F. (2000). A differentiated model of giftedness and talent. Year 2000 Update.

Gardner, H. (2011). Frames of mind: The theory of multiple intelligences. Basic books.

Gardner, H. E. (2000). Intelligence reframed: multiple int. Perseus Books Group.

Gilliam, J. E., Carpenter, B. O., \& Christensen, J. R. (1996). Gifted and Talented Evaluation Scales: A norm-referenced procedure for identifying gifted and talented students. Austin, TX: PRO-ED.

Gruber, H. E. (1986). Self-construction of the extraordinary. R. J. Sternberg and J. E.

Hambleton, R. K. (2005). Issues, designs, and technical guidelines for adapting tests into multiple languages and cultures. İçinde R. K. Hambleton, P. F. Merenda ve C. D. Spielberger (Ed.). Adapting educational and psychological tests for cross-cultural assessment. New Jersey: Lawrence Erlbaum Associates, Inc.

Hambleton, R. K., \& Patsula, L. (1999). Increasing the validity of adapted tests: Myths to be avoided and guidelines for improving test adaptation practices. Association of Test Publishers, 1(1), 1-13.

Heller, K. A. (Ed.). (2001). Hochbegabung im Kindes- und Jugendalter [High ability in childhood and youth] (2nd edition). Göttingen: Hogrefe

Heller, K. A., \& Schofield, N. J. (2008). Identification and nurturing the gifted from an international perspective. Pfeiffer, S. (Ed) In Handbook of giftedness in children, (pp. 93-114). Springer US. http://dx.doi.org/10.1007/978-0-387-74401-8_6

Heller, K. A., Perleth, C., \& Lim, T. K. (2005). The Munich model of giftedness designed to identify and promote gifted students. In R.J. Sternberg \& J. E. Davidson (Ed.), Conceptions of giftedness (2nd edition, pages 147-170). New York: Cambridge University Press. http://dx.doi.org/10.1017/CBO9780511610455.010

Hodge, R. D., \& Cudmore, L. (1986). The use of teacher-judgment measures in the identification of giftedpupils. Teaching and Teacher Education, 2, 181-196. http://dx.doi.org/10.1016/0742-051X(86)90016-8 
Hu, L., \& Bentler, P. M. (1998). Fit indices in covariance structure modeling: Sensitivity to underparameterized model misspecification. Psychological Methods, 3, 424-453. http://dx.doi.org/10.1037/1082-989X.3.4.424

Jarosewich, T., Pfeiffer, S. I., \& Morris, J. (2002). Identifying gifted students using teacher rating scales: a review of existing instruments. Journal of Psycho-educational Assessment, 20(4), 322-336. http://dx.doi.org/10.1177/073428290202000401

Kaufman, A. S., \& Harrison, P. L. (1986). Intelligence tests and gifted assessment: What are the positives? Roeper Review, 8, 154-159. http://dx.doi.org/10.1080/02783198609552961

Kline, P. (2014). An easy guide to factor analysis. Routledge.

Levent, F. (2013). Üstün yetenekli çocukları anlamak - üstün yetenekli çocuklar sarmalında aile, eğitim sistemi ve toplum (2.Baskı). Ankara: Nobel Publisher.

Matthew, J. L., Golin, A. K., Moore, M. W., \& Baker, C. (1992). Use of SOMPA in identification of gifted African-American children. Journal for the Education of the Gifted, 15(4), 344-356. http://dx.doi.org/10.1177/016235329201500404

Naglieri, J. A., \& Das, J. P. (1997). Das-Naglieri cognitive assessment system. Itasca, IL: Riverside Publishing.

Peters, S. J., \& Gentry, M. (2009). Identifying gifted, talented, and high-ability student from low-income families. Paper presented at the 18th World Conference for Gifted and Talented Children, Vancouver, Canada.

Pfeiffer, S. I. (2008). Handbook of giftedness in children. Psychoeducational theory, research and best practices. New York: Springer Science+Business Media. http://dx.doi.org/10.1007/978-0-387-74401-8

Pfeiffer, S. I. (2015). Essentials of gifted assessment. Hoboken, NJ: Wiley.

Pfeiffer, S. I., Petscher, Y., \& Jarosewich, T. (2007). The gifted rating scales-preschool/kindergarten form: An analysis of the standardization sample based on age, gender, and race. Roeper Review, 29(3), 206-211. http://dx.doi.org/10.1080/02783190709554410

Pfeiffer. S., \& Jarosewich, T. (2003). Gifted Rating Scales. Pearson.

Renzulli, J. S. (1999). What is this thing called giftedness, and how do we develop it? A twenty-five year perspective. Journal for the Education of the Gifted, 23(1), 3-54. http://dx.doi.org/10.1177/016235329902300102

Ryser, G. R., \& McConnell, K. (2004). Scales for Identifying Gifted Students: Ages 5 through 18. Waco, TX: Prufrock Press.

Sak, U. (2014). Üstün zekâlılar, özellikleri, tanılanmaları, eğitimleri (4rd edition). Ankara: Vize Publiser.

Schofield, N. J., \& Hotulainen, R. (2004). Does all cream rise? The plight of unsupported gifted children. Psychology Science, 46, 379-386.

Siu, A. F. (2010). The Reliability and Validity of a Chinese-Translated Version of the Gifted Rating ScalePreschool/Kindergarten Form. Journal of Psychoeducational Assessment, 28(3), 249-258. http://dx.doi.org/10.1177/0734282909345832

Stapf, A. (2003). Hochbegabte Kinder [Highly gifted children]. München: C.H. Beck.

Sternberg, R. J., \& Detterman, D. K. (1986). What is intelligence?. Norwood, NJ: Abley Publishing Corporation.

Sternberg, R. J., \& Zhang, L. F. (1995). What do we mean by giftedness? A pentagonal implicit theory. Gifted Child Quarterly, 39(2), 88-94. http://dx.doi.org/10.1177/001698629503900205

Sternberg, R. J., Jarvin, L., \& Grigorenko, E. L. (2010). Explorations in giftedness. Cambridge University Press. http://dx.doi.org/10.1017/cbo9780511778049

Sutherland, M. (2008). Developing the gifted and talented young learner. Sage.

Tannenbaum, A. J. (1986). Giftedness: A psychosocial approach. İçinde R. J. Sternberg \& J. E. Davidson (Ed.), Conceptions of giftedness (pp. 21-52).New York: Cambridge University Press.

Tekin, H. (1977). Eğitimde Ölçme ve Değerlendirme. Ankara: Mars Matbaası.

Winner, E. (1996). The miseducation of our gifted children, Education Week, 16(7), 44.

Yang, Y. (2009). Identification of young, gifted children: An analysis of instruments and recommendations for practice. Identification Young Children, (1).

\section{$(\mathrm{cc}) \mathrm{BY}$}

This work is licensed under a Creative Commons Attribution 3.0 License. 